\title{
Intraventricular Pressure Gradients in Heart Failure
}

\author{
M. GUERRA ${ }^{1}$, C. BRÁS-SILVA ${ }^{1}$, M. J. AMORIM ${ }^{1}$, C. MOURA ${ }^{1}$, P. BASTOS ${ }^{1}$, \\ A. F. LEITE-MOREIRA ${ }^{1}$
}

${ }^{1}$ Department of Physiology and Cardiothoracic Surgery, Cardiovascular R\&D Unit, Faculty of Medicine, University of Porto, Porto, Portugal

Received February 18, 2013

Accepted July 4, 2013

On-line September 10, 2013

\section{Summary}

The aim of the present study was to characterize intraventricular pressure gradients (IVPGs) in an animal model of chronic heart failure. New Zealand rabbits were treated with doxorubicin (heart failure group, $n=5$ ) or saline (control group, $n=5$ ) and instrumented with pressure catheters placed in the apex and outflow-tract of left ventricle (LV) and with sonomicrometer crystals placed in the apex and base of the LV free wall. In heart failure animals, ventricular filling was delayed and slower when compared with control animals. Moreover, the physiological nonuniformity observed between apical and basal segments in normal hearts was abolished in failing hearts. Simultaneously, physiological IVPGs observed during normal ventricular filling were entirely lost in heart failure animals. During ventricular emptying physiological nonuniformity between apical and basal segments observed in control animals was also abolished in heart failure animals. In failing hearts minimal length occurred later and almost at same time both in apical and in basal myocardial segments. Simultaneously, the characteristic IVPG pattern observed in healthy hearts during systole, which promotes ventricular emptying, was not observed in failing hearts. The present study showed that diastolic IVPGs, a marker of normal ventricular filling, and systolic IVPGs, a marker of normal ventricular emptying, are abolished in heart failure.

\section{Key words}

Intraventricular • Gradients • Heart failure • Diastole • Systole • Myocardial segments

\section{Corresponding author}

A. F. Leite-Moreira, Department of Physiology and Cardiothoracic Surgery, Cardiovascular R\&D Unit, Faculty of Medicine, University of Porto, Alameda Professor Hernâni Monteiro, 4200-319 Porto, Portugal. Fax: 00351225513646. E-mail: amoreira@med.up.pt

\section{Introduction}

Courtois et al. (1988) described for the first time, in a canine model, intraventricular pressure gradients (IVPGs) during diastole and later showed that these diastolic gradients were diminished by ischemia and related to systolic function (Courtois et al. 1990). Recently, we extended those observations also in an animal model. We confirmed not only the existence of diastolic but also systolic IVPGs in the left ventricle (LV) and demonstrated, for the first time, that they are modulated by physiological nonuniformity (Brutsaert $e t$ al. 1987) between basal and apical myocardial segments (Guerra et al. 2013). Moreover, we showed that diastolic and systolic IVPGs, a marker of normal segmental function, can be attenuated, lost entirely or even reversed when ventricular emptying is opposed by afterload elevations or after regional acute ischemia (Guerra et al. 2013).

Furthermore, Firstenberg et al. (2008) showed that improvements in LV systolic and diastolic function, through surgical myocardial revascularization in patients with ischemic cardiomyopathy, correlate directly with the recovery of diastolic IVPGs. Rovner et al. (2005) also demonstrated that diastolic IVPGs augmentation and LV relaxation improvement with exercise are significantly impaired in heart failure patients. However, systolic and diastolic IVPGs were never carefully observed and characterized, namely their magnitude and their behavior in the presence of systolic and/or diastolic dysfunction, in chronic models of heart failure (Stugaard et al. 1993, Steine et al. 2002).

In fact, the practical value of IVPGs in 
understanding ventricular pathophysiology is enhanced by the recognition of its general applicability and quantification not only in acute models, but also in chronic models (De Boeck et al. 2005, Yotti et al. 2005a,b). Diastolic and systolic IVPGs may reflect intrinsic properties and chronic dysfunction of the LV and not only an acute transvalvular flow disorder (Firstenberg et al. 2001, Guerra et al. 2011b). In this setting, the present study was conducted to characterize diastolic and systolic IVPGs in an animal model of chronic heart failure, and correlate IVPGs with diastolic and systolic segmental LV dysfunction and nonuniformity.

\section{Methods}

The investigation conforms to the Guide for the Care and Use of Laboratory Animals published by the US National Institutes of Health (NIH publication no. 85-23, Revised 1996), and all animals received human care in compliance with the European Convention on Animal Care. Study was also approved by the Ethics Committee of our University.

\section{Chronic heart failure model}

A well-documented regimen was used for the induction of heart failure due to doxorubicin toxicity (Arnolda et al. 1985, Brás-Silva et al. 2008). Adult male New Zealand White rabbits (Oryctolagus cuniculus, $3.0 \pm 0.2 \mathrm{~kg}$ ) received doxorubicin via a marginal ear vein by bolus injection $(1 \mathrm{mg} / \mathrm{kg})$ twice weekly for 8 weeks $(n=5)$ followed by a washout period of 1 week. Control rabbits $(n=5)$ received the vehicle $(0.9 \%$ saline $)$ in equivolumetric doses over the same period. All animals were evaluated by echocardiography at the beginning and every two weeks during the administration of doxorubicin or vehicle. Echocardiographic examination was performed as previously described (Fontes-Sousa et al. 2009). Briefly, the rabbits were lightly anesthetized with an intramuscular combination of ketamine hydrochloride $(2 \mathrm{mg} / \mathrm{kg})$ and medetomidine hydrochloride $(0.15 \mathrm{mg} / \mathrm{kg})$, being allowed to breath spontaneously. The animals were placed prone on a table with an area removed so that the ultrasound probe could be brought from below and placed on a shaved area of the anterior chest wall. The echocardiograms were obtained using a $7.5 \mathrm{MHz}$ transducer (Vivid 3 General Electrics echocardiograph, Portugal) and the examination was performed from the right parasternal short-axis view. Two-dimensional guided M-mode tracings were made just below the mitral valve at the level of the papillary muscles for measurements of the left ventricular internal diameter and the left ventricular wall was free in diastole and systole. Three representative cycles were measured and averaged for each rabbit at each time point. Analyzed parameters were: heart rate, anterior and posterior end-diastolic and end-systolic wall thickness, left ventricular end-systolic and end-diastolic diameters, and fractional shortening.

\section{Experimental preparation}

Animal preparation

The instrumentation of the animals for hemodynamic studies was performed one week after the last administration of the vehicle $(n=5)$ or doxorubicin $(n=5)$, respectively, as previously described (LeiteMoreira and Correia-Pinto 2001). In summary, animals were premedicated with ketamine hydrochloride (50 mg kg ${ }^{-1}$, I.M., Ketalar ${ }^{\circledR}$, Pfizer Limited) and xylazine hydrochloride (5 mg kg-1, I.M., Rompum ${ }^{\circledR}$, Bayer). A femoral vein was cannulated, and a intravenous solution containing $20 \mathrm{meq} \mathrm{KCl}$ and 40 meq $\mathrm{NaHCO}_{3}$ in $500 \mathrm{ml}$ of $0.9 \% \mathrm{NaCl}$ was administrated at a rate of $8 \mathrm{ml} \mathrm{kg} \mathrm{h}^{-1}$ to compensate for perioperative fluid losses. A tracheostomy was performed, and mechanical ventilation was initiated (Harvard Small Animal Ventilator, model 683), delivering oxygen-enriched air. Respiratory rate and tidal volume were adjusted to keep arterial blood gases and $\mathrm{pH}$ within physiological limits. General anesthesia was maintained by intravenous infusion of midazolam $\left(0.07 \mathrm{mg} \mathrm{kg}^{-1} \mathrm{~h}^{-1}\right.$, Midazolam B. Braun), fentanil (0.003 mg kg-1 $\mathrm{h}^{-1}$, Fentanil B. Braun) and vecuronium $\left(0.1 \mathrm{mg} \mathrm{kg}^{-1} \mathrm{~h}^{-1}\right.$, Norcuron $\AA$, Organon) to achieve adequate depth of anesthesia for absence of a corneal reflex. A 20 gauge catheter was inserted in the right femoral artery and connected to a pressure transducer to monitor heart rate and arterial pressure and to obtain samples for blood gas analysis. The heart was exposed by a median sternotomy, and the pericardium was opened wide. A limb lead electrocardiogram between the left leg electrode and the right arm electrode (DII) was recorded throughout. Transient aortic constrictions were performed by abruptly occluding the aorta with a silk suture placed around the ascending aorta during the diastole separating two heartbeats. This was achieved by pushing a plastic tube against the aorta with one hand while pulling the silk suture with the other hand. Aortic constriction was quickly released to avoid neurohumoral reflex changes in cardiac function (Correia-Pinto et al. 
2006). Peak systolic pressure of isovolumetric heartbeats, which can be obtained with aortic occlusions, is a sensitive index of left ventricular contractility.

\section{Pressure measurements}

Two 3 French high-fidelity micromanometers (SPR-524; Millar Instruments, Houston, TX, USA) were inserted through an apical puncture wound into the LV cavity. One was pulled carefully back towards the endocardium and secured in place with a purse-string suture to measure apical left ventricular pressure (LVP). The other was introduced until we could see the impact from the aortic valve on the pressure trace. The catheter then was pulled back $3 \mathrm{~mm}$ below the aortic valve so that it was located in the LV outflow tract to measure basal LVP. The pressure transducers were calibrated against a mercury column and zeroed after stabilization for $30 \mathrm{~min}$ in a water bath at body temperature. The zero was set at the level of the right atrium. Recordings were made with respiration suspended at end expiration. Parameters were converted online to digital data with a sampling frequency of $1 \mathrm{kHz}$. Left ventricular pressures were measured at end diastole $\left(\mathrm{LVP}_{\mathrm{ED}}\right)$, at pressure nadir $\left(\mathrm{LVP}_{\min }\right)$ and at peak systole $\left(\mathrm{LVP}_{\max }\right)$. Peak rates of LV pressure rise $\left(\mathrm{dP} / \mathrm{dt}_{\max }\right)$ and pressure fall $\left(\mathrm{dP} / \mathrm{dt}_{\min }\right)$, as well as time to $\mathrm{dP} / \mathrm{dt}_{\min }$, were also measured. Relaxation rate was estimated with the time constant $\tau$ by fitting the isovolumetric pressure fall to a monoexponential function. We recorded the IVPG continuously as apical minus outflow-tract LVP. Peak and average (area divided by duration) IVPGs were calculated during diastolic and systolic phases of the cardiac cycle.

\section{Sonomicrometry}

Regional ventricular function was measured with two pairs of ultrasonic segment length gauges implanted in the circumferential direction of apical and basal left ventricular anterior midwall and connected to a sonomicrometer amplifier system (Triton Technology, San Diego, CA, USA). At the end of the experiment, the animal was euthanized by administration of an overdose of anesthetic agents, and the positions of the crystals and micromanometers were verified at postmortem examination. Segment lengths were measured at the end diastole (ED length), at $\mathrm{dP} / \mathrm{dt}_{\max }$ and at mitral valve opening (MVO). Minimal segment length (Length ${ }_{\min }$ ) was measured as the minimal length preceding or coinciding with peak $-\mathrm{dP} / \mathrm{dt}_{\min }$. Fractional shortening was calculated as the percentage segment length change from end diastole to $\mathrm{dP} / \mathrm{dt}_{\min }$.

\section{Experimental protocol}

After complete instrumentation, we allowed the animal preparation to stabilize for $30 \mathrm{~min}$ before the beginning of the experimental protocol, which consisted in measuring apex to outflow-tract pressure gradients and apical and basal myocardial segment lengths in control and heart failure animals during baseline and afterloaded heartbeats. The animals were not paced, but heart rate did not vary significantly during the experimental protocol.

\section{Statistical analysis}

Statistical analysis was performed using SPSS 17.0 software. Group data are presented as means \pm SEM and were compared using two-way ANOVA. Student-Newman-Keuls test was selected to perform pairwise multiple comparisons when significant differences were detected. Statistical significance was assumed at a two tailed value of $\mathrm{P}<0.05$.

\section{Results}

\section{Cardiac hemodynamics and echocardiography}

The hemodynamic features of the experimental groups are summarized in Table 1. In comparison with the control group, the heart failure group presented a lower systolic pressure, $\mathrm{dP} / \mathrm{dt}_{\max }$, peak systolic isovolumetric pressure and fractional shortenning. The left ventricular filling pressure, as estimated by left ventricular end-diastolic pressure, was increased in failing hearts, whereas the $\mathrm{dP} / \mathrm{dt}_{\min }$ was decreased and the relaxation time constant $\tau$ was increased. Furthermore, the echocardiographic evaluation in the heart failure group demonstrated a progressive increase of the end-diastolic (from $14.2 \pm 0.3$ to $15.2 \pm 0.3 \mathrm{~mm}$ ) and end-systolic (from $9.9 \pm 0.2$ to $11.1 \pm 0.3 \mathrm{~mm}$ ) short-axis diameters and a reduction in fractional shortening (from $32 \pm 1$ to $26 \pm 1 \%$ ) and ejection fraction (from $64 \pm 1$ to $56 \pm 2 \%$ ) of the left ventricle. This was consistent with the presence of dilated cardiomyopathy and heart failure. Moreover, in the present study the animals had clear signs of heart failure such as ruffled hair, labored ventilation, ascites and pleural effusion. 
Table 1. Systolic and diastolic parameters in control and heart failure animals.

\begin{tabular}{|c|c|c|c|c|}
\hline & \multicolumn{2}{|c|}{ Control } & \multicolumn{2}{|c|}{ Heart failure } \\
\hline & Apex & Outflow tract & Apex & Outflow tract \\
\hline$L V P_{E D}(m m H g)$ & $3.3 \pm 0.2$ & $3.2 \pm 0.3$ & $3.9 \pm 0.2^{\alpha}$ & $4.0 \pm 0.2^{\alpha}$ \\
\hline$d P / d t_{\max }(m m H g / s)$ & $3791 \pm 667$ & $3669 \pm 627$ & $1187 \pm 182^{\alpha}$ & $1103 \pm 155^{\alpha}$ \\
\hline$L V P_{\max }(m m H g)$ & $80.7 \pm 4.6$ & $80.8 \pm 4.7$ & $49.1 \pm 5.5^{\alpha}$ & $48.6 \pm 5.1^{\alpha}$ \\
\hline$d P / d t_{\min }(m m H g / s)$ & $-3598 \pm 664$ & $-4631 \pm 564^{\beta}$ & $-1070 \pm 241^{\alpha}$ & $-1098 \pm 234^{\alpha}$ \\
\hline$L V P_{I S O}(\mathrm{~mm} \mathrm{Hg} / \mathrm{s})$ & $148.9 \pm 9.2$ & $149.7 \pm 9.8$ & $84.6 \pm 13.5^{\alpha}$ & $82.6 \pm 11.3^{\alpha}$ \\
\hline Time to $d P / d t_{\min }(\mathrm{ms})$ & $140 \pm 2$ & $129 \pm 1^{\beta}$ & $191 \pm 11^{\alpha}$ & $190 \pm 9^{\alpha}$ \\
\hline$L V P_{\min }(m m H g)$ & $2.7 \pm 0.6$ & $2.0 \pm 1.6$ & $2.9 \pm 0.4$ & $3.3 \pm 0.5$ \\
\hline Time to $L V P_{\min }(\mathrm{ms})$ & $214 \pm 8$ & $231 \pm 4^{\beta}$ & $268 \pm 9^{\alpha}$ & $272 \pm 7^{\alpha}$ \\
\hline$\tau(m s)$ & $15.0 \pm 1.3$ & $10.6 \pm 0.6^{\beta}$ & $30.4 \pm 1.9^{\alpha}$ & $28.4 \pm 2.2^{\alpha}$ \\
\hline ED length $(\mathrm{mm})$ & $6.90 \pm 0.33$ & $7.35 \pm 0.89$ & $7.33 \pm 0.54$ & $7.82 \pm 1.22$ \\
\hline Length at $d P / d t_{\max }(\mathrm{mm})$ & $6.97 \pm 0.27$ & $7.39 \pm 0.67$ & $7.44 \pm 0.76$ & $7.98 \pm 0.79$ \\
\hline Length $_{\min }(\mathrm{mm})$ & $5.89 \pm 0.34$ & $6.28 \pm 0.78$ & $6.92 \pm 1,38$ & $6.72 \pm 1,64$ \\
\hline Time to length ${ }_{\min }(\mathrm{ms})$ & $213 \pm 10$ & $170 \pm 16^{\beta}$ & $268 \pm 86^{\alpha}$ & $291 \pm 56^{\alpha}$ \\
\hline Length at $d P / d t_{\min }(\mathrm{mm})$ & $6.20 \pm 0.32$ & $6.32 \pm 0.42$ & $6.99 \pm 1.22$ & $7.12 \pm 0.96$ \\
\hline Length at $M V O(\mathrm{~mm})$ & $6.00 \pm 0.20$ & $6.22 \pm 0.23$ & $6.78 \pm 0.98$ & $6.98 \pm 1.43$ \\
\hline Fractional shortenning (\%) & $12.7 \pm 1.9$ & $14.3 \pm 1.1$ & $6.2 \pm 2.9^{\alpha}$ & $7.9 \pm 1.3^{\alpha}$ \\
\hline Heart rate (bpm) & \multicolumn{2}{|c|}{$170 \pm 11$} & \multicolumn{2}{|c|}{$181 \pm 7$} \\
\hline
\end{tabular}

${ }^{\alpha} \mathrm{P}<0.05$ versus normal; ${ }^{\beta} \mathrm{P}<0.05$ versus apex. Abbreviations: $\mathrm{LVP}_{\mathrm{ED}}$, end diastolic left ventricular pressure; $d P / d t_{\text {max }}$ peak rate of left

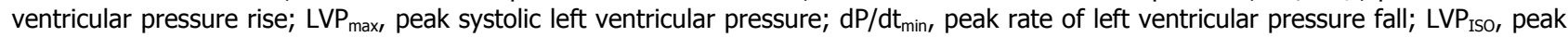
systolic pressure in a isovolumetric beat; $L P_{\min }$, left ventricular pressure nadir; $\mathrm{T}$, time constant of isovolumetric relaxation rate; ED length, end diastolic segment length; Length ${ }_{\min }$, minimal segment length; MVO, mitral valve opening.

Table 2. Apex-to-outflow tract mean pressure gradients (in $\mathrm{mm} \mathrm{Hg}$ ) throughout the cardiac cycle at baseline and during afterload elevation in control and heart failure animals.

\begin{tabular}{|c|c|c|c|c|c|}
\hline & \multicolumn{3}{|c|}{ Diastole } & \multicolumn{2}{|c|}{ Systole } \\
\hline & $\begin{array}{c}\text { Early } \\
\text { diastole }\end{array}$ & $\begin{array}{c}\text { Ventricular } \\
\text { filling }\end{array}$ & $\begin{array}{c}\text { Atrial } \\
\text { contraction }\end{array}$ & $\begin{array}{c}\text { Rapid } \\
\text { ejection }\end{array}$ & $\begin{array}{c}\text { Slow } \\
\text { ejection }\end{array}$ \\
\hline \multicolumn{6}{|l|}{ Control } \\
\hline Baseline & $-5.1 \pm 0.7$ & $+3.4 \pm 0.2$ & $+0.6 \pm 0.1$ & $+0.5 \pm 0.1$ & $-0.9 \pm 0.1$ \\
\hline Afterload & $-1.5 \pm 0.3^{\alpha}$ & $+3.7 \pm 0.2$ & $+0.5 \pm 0.1$ & $-0.8 \pm 0.1^{\alpha}$ & $-0.9 \pm 0.1$ \\
\hline \multicolumn{6}{|l|}{ Heart failure } \\
\hline Baseline & $-0.5 \pm 0.1^{\beta}$ & $+0.1 \pm 0.1^{\beta}$ & $+0.4 \pm 0.1$ & $+1.0 \pm 0.2$ & $+0.7 \pm 0.2^{\beta}$ \\
\hline Afterload & $-0.5 \pm 0.2^{\beta}$ & $+0.1 \pm 0.2^{\beta}$ & $+0.4 \pm 0.2$ & $+2.3 \pm 0.3^{\alpha, \beta}$ & $+1.8 \pm 0.3^{\alpha, \beta}$ \\
\hline
\end{tabular}

${ }^{\alpha} \mathrm{P}<0.05$ versus baseline; ${ }^{\beta} \mathrm{P}<0.05$ versus control.

\section{IVPGs changes in heart failure}

Figure 1 represents left ventricular apical and outflow tract pressures, as well as, simultaneous recording of the apex-to-outflow tract IVPG along cardiac cycle in two representative examples, one of a normal and one of a heart failure animal. Table 2 summarizes mean IVPGs throughout the cardiac cycle in control and heart failure animals during baseline and afterloaded cardiac beats.

In healthy hearts of control animals, during the rapid phase of ventricular filling, we recorded a $-5.1 \pm 0.5 \mathrm{~mm} \mathrm{Hg}$ IVPG from the outflow-tract to the 
apex. Later, when apical pressure started to rise, the outflow-tract pressure continued to fall, thus creating a $+3.6 \pm 0.2 \mathrm{~mm} \mathrm{Hg}$ apex to outflow-tract pressure gradient. During systole we recorded a biphasic IVPG pattern, manifested as a positive gradient $(+0.6 \pm 0.1 \mathrm{~mm} \mathrm{Hg})$ from apex to outflow-tract during rapid ejection, which was followed by a negative gradient from the outflow-tract to the apex during the slow ejection phase $(-0.8 \pm 0.1 \mathrm{~mm} \mathrm{Hg})$.
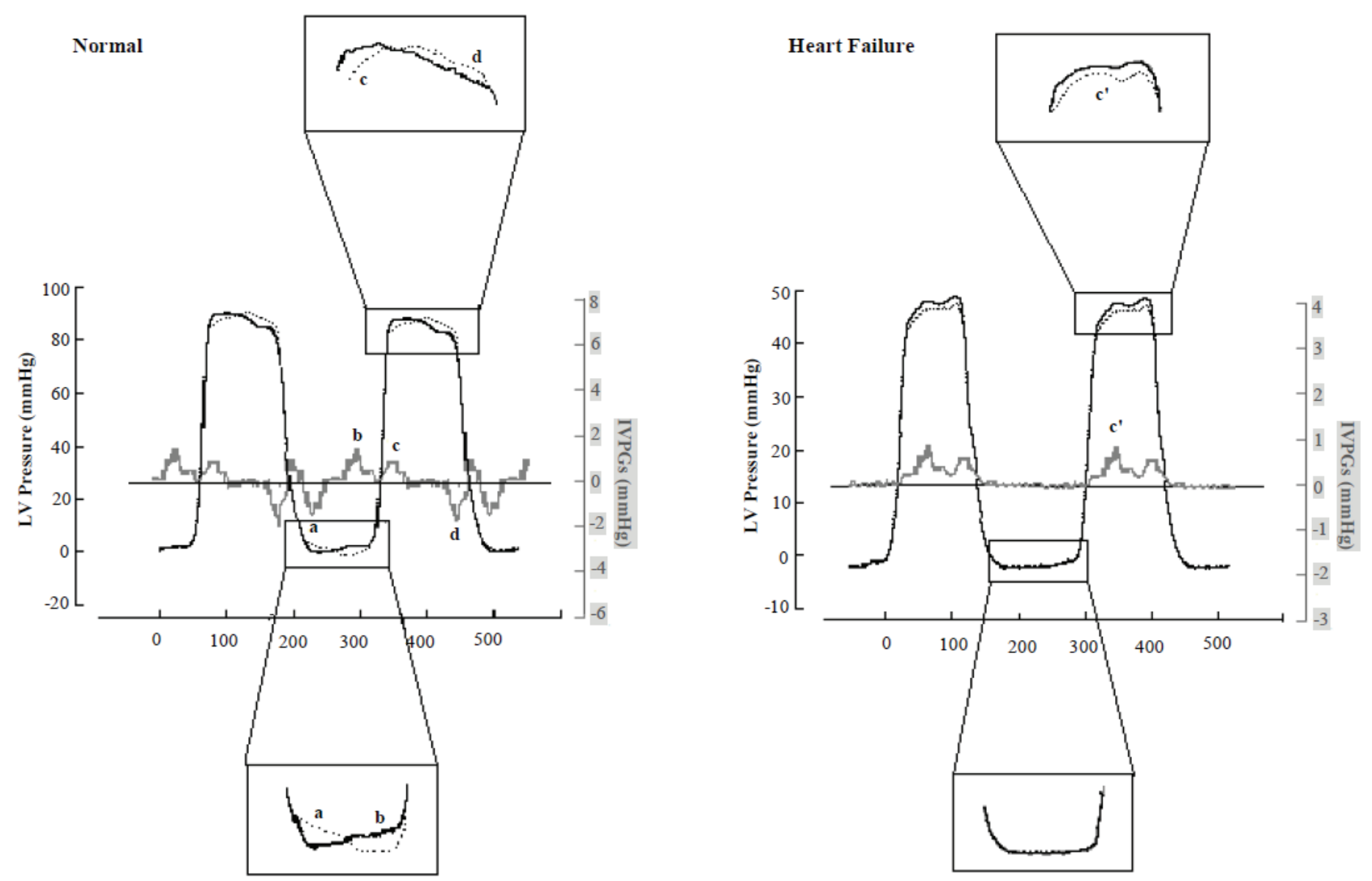

Fig. 1. Left ventricular apical (-) and outflow tract (----) pressures and simultaneous recording of apex-to-outflow tract IVPG (gray) along cardiac cycle in a representative normal vs heart failure animal. Normal: During diastole we observed a significant outflow tractto-apex IVPG in the early diastole (a) and an apex-to-outflow tract IVPG in the late diastole (b); during early systole we recorded an IVPG from apex-to-outflow (c) which inverts during late systole (d). Heart Failure: Diastolic IVPGs observed during normal ventricular filling were entirely lost in failing hearts, while during systole we observed only one apex-to-outflow-tract gradient throughout ventricular emptying $\left(\boldsymbol{c}^{\prime}\right)$.

In failing ventricles of heart failure animals, diastolic ventricular filling was delayed and slower, as indicated by the increase in times to apical and basal peak $\mathrm{dP} / \mathrm{dt}_{\min }$ and to LVP nadir. Moreover, the nonuniformity (measured as distinct timings at which minimum length was achieved between different ventricular segments during cardiac cycle) observed between apical and basal segments in healthy hearts was abolished in heart failure. In fact, faster outflow-tract relaxation (assessed by $\mathrm{dP} / \mathrm{dt}_{\min }$ and by the time constant $\tau$ ) observed in healthy hearts was not observed in failing hearts where relaxation occurred at the same moment in the apex and in the outflow-tract (Table 1, Time to $\mathrm{LVP}_{\min }$ ). Simultaneously, diastolic IVPGs were entirely lost in heart failure animals, and no differences were recorded between outflow-tract and apical LV pressures during ventricular filling (Fig. 1, Heart Failure). During ventricular emptying faster contraction of basal in comparison to apical myocardial segments recorded in healthy hearts (assessed by a shorter time to minimal length for a similar myocardial shortening) was also abolished in heart failure animals. In failing hearts minimal length occurred later and almost at same time both in apical and in basal myocardial segments (Table 1, Time to lenght ${ }_{\text {min }}$ ). Simultaneously, the physiological biphasic IVPG pattern observed in healthy hearts during systole was not observed in failing hearts (Fig. 1, Heart Failure). Additionally, the response to afterload elevation was also 
distinct in the failing hearts, which may represent a sensitive indicator of LV contractility impairment (Table 2).

\section{Discussion}

The present study showed that diastolic IVPGs, a marker of normal ventricular filling, and systolic IVPGs, a marker of normal ventricular emptying, are abolished in failing hearts.

Previously, we demonstrated that diastolic and systolic IVPGs are modulated by physiological nonuniformity between basal and apical myocardial segments and that IVPGs can be attenuated, lost entirely or even reversed when ventricular emptying is opposed by afterload elevations or after regional acute ischemia (Guerra et al. 2013). So, we hypothesized that any condition that interferes with the normal segmental function, such as chronic heart failure, might be expected to alter the physiological IVPGs throughout the cardiac cycle. In fact, dilated ventricles are poor suction pumps, aspirating a relatively small volume in early filling and compensating with atrial contraction and a resting tachycardia to maintain cardiac output (Little 2005). Healthy ventricles store greater amounts of elastic energy during systole and are therefore more effective suction pumps during diastole (Gilbert and Glantz 1989). In this context, reduced diastolic IVPGs are the consequence not only of a lower impulse due to depressed elastic recoil, but also of relatively higher deleterious convective forces and impaired ventricular relaxation, which adversely affect LV filling (Nikolic et al. 1995).

In our animal model, the progression of cardiac dysfunction was monitored echocardiographically to estimate morphologic and functional alterations during the development of heart failure. Hemodynamic studies performed two weeks after the last administration of doxorubicin and the last echocardiographic evaluation clearly showed the presence of systolic and diastolic dysfunction in heart failure animals. In comparison with the control group, the heart failure group presented significantly lower systolic pressures, dP/dtmax, peak systolic isovolumetric pressures and fractional shortening, consistent with the presence of dilated cardiomyopathy and heart failure. In fact, doxorubicin is an anthracycline widely used in cytostatic treatments which causes a dose-dependent cardiotoxicity and thus has been used to induce heart failure in various animal species (Gomes et al. 2012). Doxorubicin-induced cardiomyopathy is characterized by ventricular wall thinning and dilatation, and depressed systolic and diastolic function accompanied by fluid retention and by neurohumoral activation (Chekanov 1999). At the cardiac muscle level, it promotes intrinsic contractile dysfunction and reduced contractile reserve. Furthermore, doxorubicin impairs vascular as well as endocardial endothelial function and induces inflammatory reactions in the heart, leading to thrombosis in the atria and myocarditis (Gaudin et al. 1993). Multiple pathways of anthracycline-induced cardiac cellular injury have been proposed such as the release of cardiotoxic substances, which subsequently accumulate in the cardiomyocytes, the generation of free radical, lipid peroxidation, and suppression of DNA, RNA and protein synthesis (Sawyer et al. 2010, Adão et al. 2013).

In the present study the animals had clear signs of heart failure, which were more compatible with the invasive hemodynamic measurements than with the more modest echocardiographic depression. As echocardiographic recordings were performed every two weeks, the last echocardiographic evaluation was carried out two weeks before the hemodynamic measurements. Given the rapid progression of the disease after six weeks, this might explain the different phenotypes at the two distinct time points. Moreover, echocardiography is not a sensitive method for detecting significant differences of wall thickening in these small hearts.

In heart failure animals, the normal base-to-apex IVPG observed during early diastole was entirely abolished, showing impairment of ventricular filling. Late diastolic apex-to-base IVPG was also lost in failing hearts which may compromise the beginning of next ventricular emptying. In fact, diastolic IVPGs might be causally related to recoil of ventricular walls in conjunction with release of elastic energy stored during the previous systole, which generates suction and contributes to normal filling (Courtois et al. 1990). In cardiomyopathic hearts, abnormal diastolic movement of dyskinetic segments during isovolumetric relaxation could impart some motion to blood pooled in the apical and anterior regions of the ventricle and thus contribute to the alteration of the normal diastolic IVPGs (Beppu et al. 1988, Delemarre et al. 1988). Moreover, some elastic potential energy stored during systole could be prematurely lost during early diastole in failing hearts which may impair ventricular filling and abolish normal early and late diastolic IVPGs (Smiseth et al. 1998). Thus, acute or chronic ventricular dysfunction, by 
diminishing the amount of functional ventricular myocardium available for contraction and subsequent elastic recoil in one region of the ventricle, should result in loss or diminution of the diastolic IVPG in that region (Guerra et al. 2013).

During systole, the normal IVPG pattern observed in healthy hearts, and characterized by an apex to outflow-tract gradient during rapid ejection followed by an outflow-tract to apex gradient during the slow ejection phase, was also lost in failing hearts. In normal hearts, systolic IVPG pattern parallels the physiological aortic-ventricular pressure gradients observed between aorta and the LV with aortic pressure being lower than LV pressure during rapid ejection and higher during the slow ejection phase. In heart failure animals, physiological biphasic IVPGs during systole were not observed, which may impair normal ventricular emptying.

As a potential limitation, we must acknowledge that the present study was performed in anesthetized open-chest and open-pericardium animals with two pressure catheters tied at the level of the LV apex and two myocardial segment length gauges placed in the apex and base of the LV free wall. These manipulations may impair ventricular contractility, as well as, may alter longitudinal function and torsion thereby affecting apex to base gradients. We must however underscore that the catheters and segment length gauges are rather flexible and small, minimizing the negative impact on LV function. Moreover, as both groups (heart failure and control) were submitted to the same surgical manipulation such impact should have been similar, therefore making it acceptable to compare IVPGs in the two groups (Guerra et al. 2011a).

In conclusion, regional alterations in IVPGs might be an important factor in the characteristic changes that occur in intraventricular flow in specific cardiac disorders. IVPGs play a physiological role in the healthy heart that is lost in pathological conditions, which may contribute to and represent an early sign of ventricular dysfunction. In this way IVPGs recording and study may give important novel insight into the comprehension of heart failure pathophysiology. Moreover, our findings might be relevant to better understand the pathophysiology of doxorubicin-induced cardiomyopathy so that we can develop efficient protective and/or therapeutic strategies in patients treated with this chemotherapeutic agent.

\section{Conflict of Interest}

There is no conflict of interest.

\section{Acknowledgements}

This work was supported by a grant from the Portuguese Foundation for Science and Technology (FCT: PEst-C/SAU/UI0051/2011; EXCL/BIM-MEC/055/2012 throught Cardiovascular R\&D Unit) and from the European Commission (FP7-Health-2010; MEDIA261409). C. B.-S. is also supported by grants from the Portuguese Foundation for Science and Technology (PTDC/SAU-FCT/100442/2008, COMPETE, FEDER and Ciência 2008) and from the University of Porto/Santander Totta.

\section{References}

ADÃO R, DE KEULENAER G, LEITE-MOREIRA A, BRÁS-SILVA C: Cardiotoxicity associated with cancer therapy: Pathophysiology and prevention strategies. Rev Port Cardiol 32: 395-409, 2013.

ARNOLDA L, MCGRATH B, COCKS M, SUMITHRAN E, JOHNSTON C: Adriamycin cardiomyopathy in the rabbit: an animal model of low output cardiac failure with activation of vasoconstrictor mechanisms. Cardiovasc Res 19: 378-382, 1985.

BEPPU S, IZUMI S, MIYATAKE K, NAGATA S, PARK YD, SAKAKIBARA H, NIMURA Y: Abnormal blood pathways in left ventricular cavity in acute myocardial infarction. Circulation 78: 157-164, 1988.

BRÁS-SILVA C, MONTEIRO-SOUSA D, DUARTE AJ, GUERRA M, FONTES-SOUSA AP, MOURA C, AREIAS JC, LEITE-MOREIRA AF: Nitric oxide and prostaglandins - important players in endothelin-1 induced myocardial distensibility. Physiol Res 57: 165-174, 2008.

BRUTSAERT DL: Nonuniformity: a physiologic modulator of contraction and relaxation of the normal heart. $J \mathrm{Am}$ Coll Cardiol 9: 341-348, 1987. 
CHEKANOV VS: A stable model of chronic bilateral ventricular insufficiency (dilated cardiomyopathy) induced by arteriovenous anastomosis and doxorubicin administration in sheep. J Thorac Cardiovasc Surg 117: 198-199, 1999.

CORREIA-PINTO J, HENRIQUES-COELHO T, RONCON-ALBUQUERQUE R JR, LEITE-MOREIRA AF: Differential right and left ventricular diastolic tolerance to acute afterload and NCX gene expression in Wistar rats. Physiol Res 55: 513-526, 2006.

COURTOIS M, KOVÁCS SJ, LUDBROOK PA: Transmitral pressure-flow velocity relation: importance of regional pressure gradients in the left ventricle during diastole. Circulation 78: 661-671, 1988.

COURTOIS M, KOVÁCS SJ, LUDBROOK PA: Physiological early diastolic intraventricular pressure gradient is lost during acute myocardial ischemia. Circulation 81: 1688-1696, 1990.

DE BOECK BW, OH JK, VANDERVOORT PM, VIERENDEELS JA, VAN DER AA RP, CRAMER MJ: Colour M-mode velocity propagation: a glance at intra-ventricular pressure gradients and early diastolic ventricular performance. Eur J Heart Fail 7: 19-28, 2005.

DELEMARRE BJ, BOT H, VISSER CA, DUNNING AJ: Pulsed Doppler echocardiographic description of a circular flow pattern in spontaneous left ventricular contrast. J Am Soc Echo 1: 114-118, 1988.

FIRSTENBERG MS, GREENBERG NL, GARCIA MJ, THOMAS JD: Relationship between ventricular contractility and early diastolic intraventricular pressure gradients: a diastolic link to systolic function. $J$ Am Soc Echocardiogr 21: 501-506, 2008.

FIRSTENBERG MS, SMEDIRA NG, GREENBERG NL, PRIOR DL, MCCARTHY PM, GARCIA MJ, THOMAS JD: Relationship between early diastolic intraventricular pressure gradients, an index of elastic recoil, and improvements in systolic and diastolic function. Circulation 104: 330-335, 2001.

FONTES-SOUSA AP, MOURA C, CARNEIRO CS, TEIXEIRA-PINTO A, AREIAS JC, LEITE-MOREIRA AF: Echocardiographic evaluation including tissue Doppler imaging in New Zealand white rabbits sedated with ketamine and midazolam. Vet J 181: 326-331, 2009.

GAUDIN PB, HRUBAN RH, BESCHORNER WE, KASPER EK, OLSON JL, BAUGHMAN KL, HUTCHINS GM: Myocarditis associated with doxorubicin cardiotoxicity. Am J Clin Pathol 100: 158-163, 1993.

GILBERT JC, GLANTZ SA: Determinants of left ventricular filling and of the diastolic pressure-volume relation. Circ Res 64: 827-852, 1989.

GOMES AC, FALCÃO-PIRES I, PIRES AL, BRÁS-SILVA C, LEITE-MOREIRA AF: Rodent models of heart failure: an updated review. Heart Fail Rev 18: 219-249, 2013.

GUERRA M, AMORIM MJ, BRÁS-SILVA C, LEITE-MOREIRA AF: Intraventricular pressure gradients along the cardiac cycle: Effects of ischemia and modulation by afterload. Exp Physiol 98: 149-160, 2013.

GUERRA M, AMORIM MJ, MOTA JC, VOUGA L, LEITE-MOREIRA A: Rationale, design and methodology for intraventricular pressure gradients study: a novel approach for ventricular filling assessment in normal and falling hearts. J Cardiothorac Surg 6: 67, 2011.

GUERRA M, SAMPAIO F, BRÁS-SILVA C, LEITE-MOREIRA AF: Left intraventricular diastolic and systolic pressure gradients. Exp Biol Med (Maywood) 236: 1364-1372, 2011.

LEITE-MOREIRA AF, CORREIA-PINTO J: Load as an acute determinant of end-diastolic pressure-volume relation. Am J Physiol Heart Circ Physiol 280: 51-59, 2001.

LITTLE WC: Diastolic dysfunction beyond distensibility: adverse effects of ventricular dilatation. Circulation 112: 2888-2890, 2005.

NIKOLIC SD, FENELEY MP, PAJARO OE, RANKIN JS, YELLIN EL: Origin of regional pressure gradients in the left ventricle during early diastole. Am J Physiol 268: 550-557, 1995.

ROVNER A, GREENBERG NL, THOMAS JD, GARCIA MJ: Relationship of diastolic intraventricular pressure gradients and aerobic capacity in patients with diastolic heart failure. Am J Physiol Heart Circ Physiol 289: 2081-2088, 2005.

SAWYER DB, PENG X, CHEN B, PENTASSUGLIA L, LIM CC: Mechanisms of anthracycline cardiac injury: can we identify strategies for cardioprotection? Prog Cardiovasc Dis 53: 105-113, 2010.

SMISETH OA, STEINE K, SANDBAEK G, STUGAARD M, GJOLBERG T: Mechanics of intraventricular filling: study of LV early diastolic pressure gradients and flow velocities. Am J Physiol 275: 1062-1069, 1998. 
STEINE K, STUGAARD M, SMISETH OA: Mechanisms of diastolic intraventricular regional pressure differences and flow in the inflow and outflow tracts. $J$ Am Coll Cardiol 40: 983-990, 2002.

STUGAARD M, SMISETH OA, RISØE C, IHLEN H: Intraventricular early diastolic filling during acute myocardial ischemia. Assessment by multigated color M-mode echocardiography. Circulation 88: 2705-2713, 1993.

YOTTI R, BERMEJO J, ANTORANZ JC, DESCO MM, CORTINA C, ROJO-ALVAREZ JL, ALLUÉ C, MARTÍN L, MORENO M, SERRANO JA, MUÑOZ R, GARCÍA-FERNÁNDEZ MA: A noninvasive method for assessing impaired diastolic suction in patients with dilated cardiomyopathy. Circulation 112: 2921-2929, 2005.

YOTTI R, BERMEJO J, DESCO MM, ANTORANZ JC, ROJO-ALVAREZ JL, CORTINA C, ALLUÉ C, RODRÍGUEZ-ABELLA $\mathrm{H}$, MORENO M, GARCÍA-FERNÁNDEZ MA: Doppler-derived ejection intraventricular pressure gradients provide a reliable assessment of left ventricular systolic chamber function. Circulation 112: 1771-1779, 2005. 